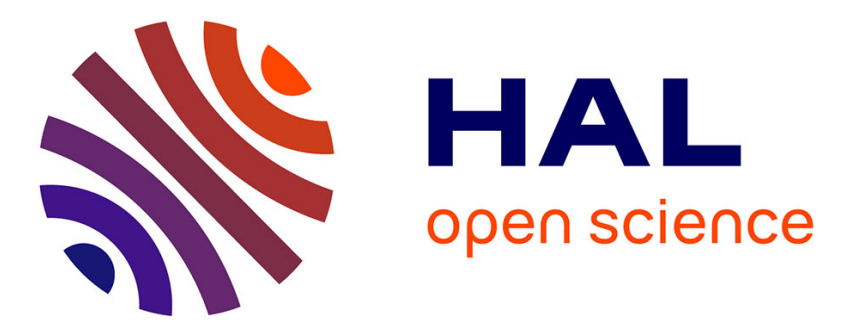

\title{
Thermogravimetric Study of Oxide Spallation for Chromium-Rich Cast Cobalt-Based and Iron-Based Alloys Oxidized at High Temperature Patrice Berthod
}

\section{- To cite this version:}

Patrice Berthod. Thermogravimetric Study of Oxide Spallation for Chromium-Rich Cast CobaltBased and Iron-Based Alloys Oxidized at High Temperature. The Open Corrosion Journal, 2009, 2, pp.61 - 70. 10.2174/1876503300902010061 . hal-02314898

\author{
HAL Id: hal-02314898 \\ https://hal.science/hal-02314898
}

Submitted on 14 Oct 2019

HAL is a multi-disciplinary open access archive for the deposit and dissemination of scientific research documents, whether they are published or not. The documents may come from teaching and research institutions in France or abroad, or from public or private research centers.
L'archive ouverte pluridisciplinaire HAL, est destinée au dépôt et à la diffusion de documents scientifiques de niveau recherche, publiés ou non, émanant des établissements d'enseignement et de recherche français ou étrangers, des laboratoires publics ou privés. 


\title{
Thermogravimetric Study of Oxide Spallation for Chromium-Rich Cast Cobalt-Based and Iron-Based Alloys Oxidized at High Temperature
}

\author{
Patrice Berthod*
}

\author{
Institut Jean Lamour (UMR CNRS 7198), Department 2 "Chemistry and Physic of Solids and Surfaces", Team "Surface \\ and Interface, Chemical Reactivity of Materials", Faculty of Science and Techniques, Nancy-University, B.P. 70239, \\ 54506 Vandoeuvre-lès-Nancy, France
}

\begin{abstract}
During temperature cycles, metallic alloys for high temperature applications are usually oxidized with formation of an external protective oxide scale, but they loose it during the cooling. This problem of oxide spallation can be studied by specific tests of cyclic oxidation but first indications can be provided by analyzing the cooling parts of thermogravimetry curves. This possibility was studied in this work for simple $\{\mathrm{Co}$ or $\mathrm{Fe}\}-30 \mathrm{wt} \% \mathrm{Cr}$ alloys containing between 0 and 0.8 wt.\% of carbon, and for two of these alloys after addition of about $5 \mathrm{wt} . \%$ of tantalum. These alloys, elaborated by foundry process, were exposed to oxidation at 1000,1100 or $1200^{\circ} \mathrm{C}$ for 50 hours, with recording of their mass gain during heating, isothermal dwell and cooling. The analysis of the cooling part of the thermogravimetry files allowed specifying several data characterizing the spallation of the external oxide, such as the temperature at which the phenomenon begins and the rate with which the mass decreases because of the loss of oxide. Metallographic data about oxidation and spallation were obtained by examination of cross-sections of the oxidized samples. Oxide spallation, characterized by its beginning's temperature and its corresponding mass loss rate, was obviously more severe for the cobalt alloys than for the iron ones, for the carbon-free alloys than for carbides-containing ones and for tantalum-containing alloys than for the tantalum-free ones. Most of these effects were explained.
\end{abstract}

Keywords: Oxide spallation, thermogravimetry, cobalt alloys, iron alloys, tantalum.

\section{INTRODUCTION}

When they are used at high temperature metallic materials are generally subjected to oxidation which can occur externally as well as internally. The external oxide scale formed on surface becomes continuous after a more or less long time, and then it reduces the rate of oxidation since the latter is now governed by diffusion of ionic species $\left(\mathrm{O}^{2-}\right.$ anions or metallic cations) through the scale [1]. Oxidation becomes slower and slower and the kinetic is of the parabolic type since it obeys the Wagner's law [2]. When elements such as aluminum or chromium are present with sufficient amounts, the continuous oxide layer separating bulk and external gas is stoichiometric (respectively $\mathrm{Al}_{2} \mathrm{O}_{3}$ or $\mathrm{Cr}_{2} \mathrm{O}_{3}$ ) [3] and the rate of oxidation is considerably lowered since diffusion of ions through the external oxide, in which ionic vacancies and interstitial ions are only the Frenkel and Schottky defects, is very slow. This is the reason why chromium or aluminum is added to the superalloys destined to work at very high temperature [4]. More precisely, in the case of chromium, which is the element added to the alloys studied in this work, it is usually considered that its content must be at least $20 \mathrm{wt} . \%$ for the nickel-based alloys and the iron-based alloys to favor the chromia-forming behavior, while cobalt-based alloys must contain at least $30 \mathrm{wt} . \% \mathrm{Cr}$ to be also chromia-former.

*Address correspondence to this author at the Institut Jean Lamour (UMR CNRS 7198), Department 2 "Chemistry and Physic of Solids and Surfaces", Team "Surface and Interface, Chemical Reactivity of Materials", Faculty of Science and Techniques, Nancy University, B.P. 70239, 54506 Vandoeuvrelès-Nancy, France; E-mail: Patrice.Berthod@lcsm.uhp-nancy.fr
Thus, the deterioration by high temperature oxidation can be prevented by choosing sufficiently high contents in chromium or aluminum in the chemical composition of the alloy. Unfortunately, the oxide growth sometimes leads to the appearance of internal stresses in the oxide scale which may involve detachments and breakdowns of this protective scale. Such phenomena occur almost always when the temperature of the alloy falls down after oxidation on long times, as encountered in cyclic oxidation as well as after a single cooling (illustrating examples in Fig. 1). The loss of the external oxide constrains the alloy to develop a new continuous external oxide when it is heated again, from the outer part of the alloy which was previously impoverished in $\mathrm{Cr}$ by the development of the first chromia scale. Then the alloy can be more threatened by a possible loss of its chromia-forming behavior. This is especially true for cobalt alloys because of the high quantity of chromium that they must contain for being chromia-former, but also for alloys based on nickel and/or iron since several weight percent of chromium can be lost in their first hundreds $\mu \mathrm{m}$ from surface because of a previous oxidation.

Thermogravimetry is more destined for specifying the oxidation rates in isothermal conditions, than for analyzing the following oxide spallation. Nevertheless this technique was successfully used in numerous previous works for characterizing oxide spallation, for example, among the most recent studies, in the case of refractory austenitic steels $[5,6]$ or of alumina-forming nickel alloys [7] thermally cycled.

The purpose of the present work is to characterize this oxide spallation during cooling after isothermal oxidation, by exploiting the cooling parts of thermogravimetry curves 


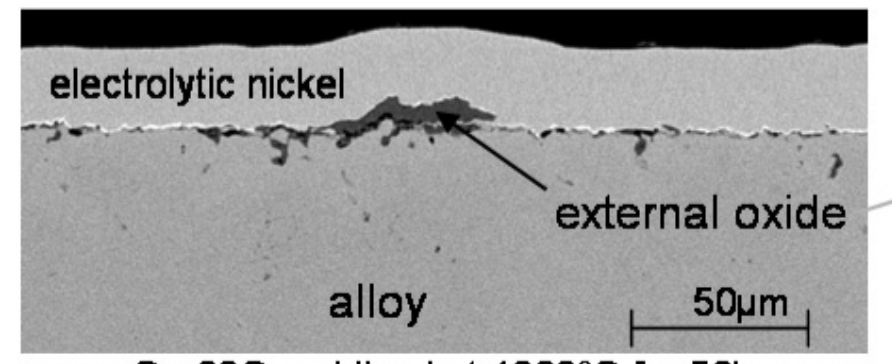

Co-30Cr oxidized at $1000^{\circ} \mathrm{C}$ for $50 \mathrm{~h}$

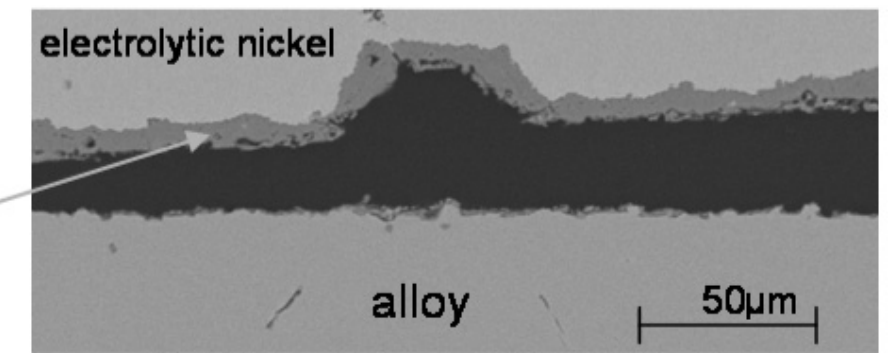

$\mathrm{Fe}-30 \mathrm{Cr}$ oxidized at $1000^{\circ} \mathrm{C}$ for $50 \mathrm{~h}$

Fig. (1). Examples of two phenomena which often occur during cooling after oxidation at high temperature: more or less severe partial loss (on the left hand) and local bending (on the right hand) of the external oxide scale.

concerning ternary alloys, of the type $\{\mathrm{Co}$ or $\mathrm{Fe}, 30 \mathrm{Cr}$ and 0 $0.8 \mathrm{C}$, in weight percent $\}$, which can be considered as simple versions of real industrial alloys for high temperature applications. The cases of a Co-based alloy and of a Fe-based alloy both containing $30 \mathrm{wt} . \% \mathrm{Cr}$ and $0.4 \mathrm{wt} . \% \mathrm{C}$ with also several weight percents of tantalum, will be also examined to reveal a possible effect of this other element on the oxide spallation phenomenon.

\section{MATERIALS AND METHODOLOGY}

The five studied cobalt-based alloys are a binary Co-30 wt. $\% \mathrm{Cr}$, three ternary $\mathrm{Co}-30 \mathrm{wt} . \% \mathrm{Cr}$ alloys containing 0.2 , 0.4 or $0.8 \mathrm{wt} . \% \mathrm{C}$, and a quaternary alloy the composition of which is $\mathrm{Co}$ (bal.)-30Cr-0.4C-5Ta (all contents in weight percents). The five studied iron-based alloys are a $\mathrm{Fe}-30 \mathrm{Cr}$ alloy, three $\mathrm{Fe}-30 \mathrm{wt} . \% \mathrm{Cr}$ alloys with also $0.2,0.4$ and $0.8 \mathrm{wt} . \% \mathrm{C}$, and a Fe-29Cr-0.4C-6Ta (in wt.\%) alloy. They were all elaborated by High Frequency (HF) induction foundry under an inert atmosphere (three hundreds millibars of pure argon), using pure elements (purity higher than $99 \%$ in mass): $\mathrm{Co}, \mathrm{Fe}, \mathrm{Cr}$ and $\mathrm{Ta}$ (Alfa Aesar), and $\mathrm{C}$ (pure graphite). Fusion and solidification were performed in the watercooled copper crucible of the HF induction furnace (CELES), and compact ingots of about $100 \mathrm{~g}$ were obtained. The microstructures of the alloys are composed of a dendritic matrix which contains the base element and a part of the chromium (and carbon) atoms, and of interdendritic $\mathrm{Cr}_{23} \mathrm{C}_{6}$ carbides (identified by microprobe), for both the ternary cobalt alloys and iron alloys. The binary alloys are single phased and the carbides of the tantalum-containing alloys are only $\mathrm{TaC}$ (controlled by microprobe).

All the ingots were cut in order to obtain parallelepipeds of about $10 \mathrm{~mm} \times 10 \mathrm{~mm} \times 3 \mathrm{~mm}$. They were polished with $\mathrm{SiC}$ grit paper (grade 1200) on their six faces and their edges and corners were smoothed with the same paper. The thermogravimetry runs were performed using a Setaram TGA-92 thermobalance, in a flow of $1.5 \mathrm{~L} \mathrm{~h}^{-1}$ of industrial air $\{80 \%$ $\left.\mathrm{N}_{2}-20 \% \mathrm{O}_{2}\right\}$. The heating rates and cooling rates were equal to respectively $20 \mathrm{~K} \mathrm{~min}^{-1}$ and $-5 \mathrm{~K} \mathrm{~min}^{-1}$, and the temperatures of the 50 hours - dwells were 1000,1100 and $1200{ }^{\circ} \mathrm{C}$.

After return to room temperature, the oxidized samples were firstly covered by a thin layer of gold (by an evaporation technique), then by a thick nickel layer (by electrochemical reduction of $\mathrm{Ni}^{2+}$ ions on cathode-polarized samples immersed in a Watts' solution). Thereafter the samples were cut without additional loss of the external oxide thanks to the mechanically resistant Ni-layer previously deposited. The two halves of each sample were embedded in a resin + hardener mixture, polished firstly with $\mathrm{SiC}$ papers (grades from 120 to 1200 ), and secondly with alumina $1 \mu \mathrm{m}$ particles. The metallographic examinations of the mounted and polished samples were done using a Scanning Electrons Microscope (SEM, type: Philips XL30) in Back Scattered Electrons mode (BSE) with an acceleration voltage of $20 \mathrm{kV}$. Bulk, sub-surface and oxide layers were observed. The identification of the different oxides, which could be of different types $\left(\mathrm{CoO}, \mathrm{Cr}_{2} \mathrm{O}_{3}, \mathrm{CoCr}_{2} \mathrm{O}_{4}\right.$ for the cobalt alloys, different iron oxides, $\mathrm{Cr}_{2} \mathrm{O}_{3}$ or $(\mathrm{Fe}, \mathrm{Cr})_{2} \mathrm{O}_{3}$ for the iron alloys, $\mathrm{CrTaO}_{4}$ when tantalum is present in the alloy), and the determination of their chemical compositions, were achieved using the Energy Dispersion Spectrometry device (EDS, Kevex) of the SEM, and by Wavelength Dispersion Spectrometry (WDS, Cameca SX50 and SX100).

The mass gain results were drawn in the $\{\Delta \mathrm{m} / \mathrm{S}$ versus $\mathrm{T}\}$ scheme, instead of the $\{\Delta \mathrm{m} / \mathrm{S}$ versus time or square root of time schemes, since attention was here focused on the mass losses during the post-dwell cooling, and not on the kinetic of isothermal oxidation. In order to correctly interpret the cooling parts of the curves a thermogravimetric run was performed in the same conditions as the real tests, but with a sample made of an inert material $\left(\mathrm{Al}_{2} \mathrm{O}_{3}\right)$ and the volume of which was similar to the studied samples. More precisely this allowed better knowing the apparent mass variations only due to the increase in Archimedes' thrust when the temperature decreases. This led to the mass gain curve displayed in Fig. (2A) and enlarged in Fig. (2B), in which one can see the apparent increase in mass during heating, the isothermal loss due to the slow volatilization of the hottest part of the platinum suspension (here during 10 hours at $1300^{\circ} \mathrm{C}$ ), and finally the decrease in mass during cooling. The last one is initially slow and linear (between $1300^{\circ} \mathrm{C}$ and almost $500^{\circ} \mathrm{C}$ ) but it accelerates more and more during the cooling between $500^{\circ} \mathrm{C}$ and the ambient temperature. If the low temperature part of the heating curve was more or less perturbed by the thermal equilibrium which was gradually established at the beginning of the experiment, the acceleration of the decrease in mass under about $500^{\circ} \mathrm{C}$ in the cooling curve is conform to the loss of the "linearity" (evolution almost linear versus $\mathrm{T}$ if $\mathrm{T}$ is far enough from $\mathrm{T}_{0}$ ) of the expression of the apparent mass of the sample and its suspension (in the hottest zone where the temperature is T):

$$
m_{\text {app }}(T)=m_{\text {app }}\left(T_{0}\right)+V \times \rho\left(T_{0}\right) \times\left(\frac{T-T_{0}}{T}\right)
$$


with $\mathrm{T}_{0}$ : the ambient temperature, $\mathrm{V}$ : the volume of the sample and of the hottest part of its suspension and $\rho\left(T_{0}\right)$ : the volume mass of air at $T_{0}$. This acceleration of mass loss (average mass loss rate equal to about $-0.4 \mu \mathrm{g} / \mathrm{cm}^{2} /{ }^{\circ} \mathrm{C}$ between $500^{\circ} \mathrm{C}$ and ambient temperature, four times higher than for the linear decrease at $\mathrm{T}>500^{\circ} \mathrm{C}$ ) must be compared to the mass loss rates in the same temperatures range observed for oxidized samples.

(A)

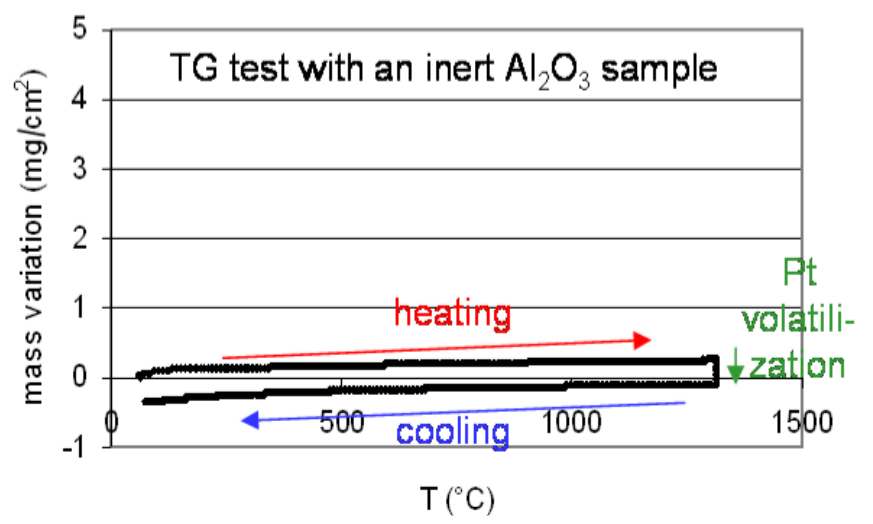

(B)

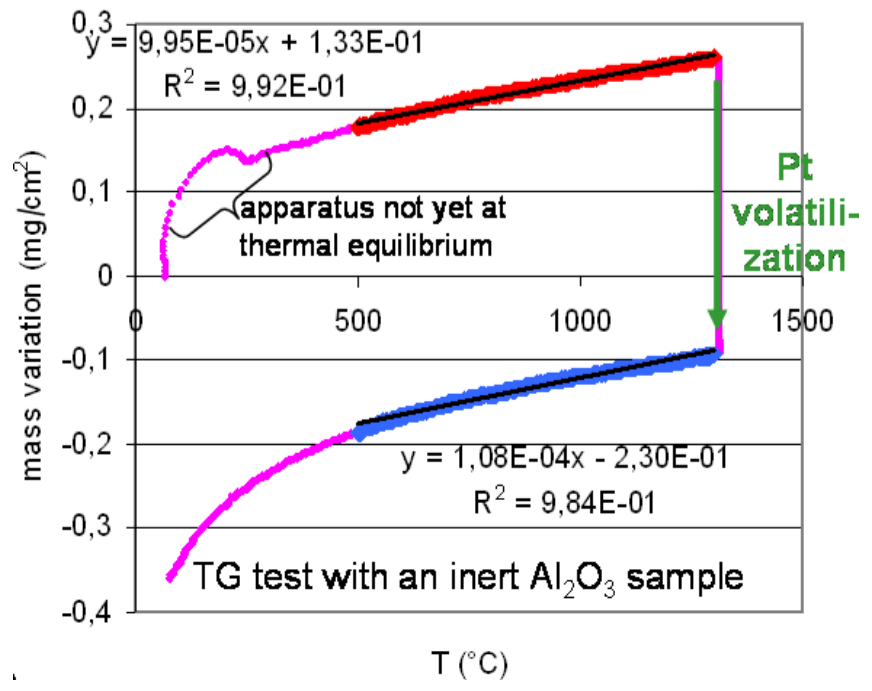

Fig. (2). Mass variations due to the Archimedes' thrust during heating and during cooling: (A) revealed by a test with an $\mathrm{Al}_{2} \mathrm{O}_{3}$ sample with the same geometry as a real alloy sample, and plotted with the same mass gain scale as for to the real alloys when tested until $1000^{\circ} \mathrm{C}$; (B) enlargement of the previous graph for revealing initial variations due to a thermal equilibrium not yet established at the beginning of the heating part, and measurement of the mass increase rates (divided by $2 \mathrm{~cm}^{2}$, typical average surface of the alloy samples) (same thermobalance as for the alloy samples, heating rate and cooling rate: $+20 \mathrm{~K} \min ^{-1}$ and $-5 \mathrm{~K} \mathrm{~min}^{-1}$, dwell at $1300^{\circ} \mathrm{C}$ during 10 hours, volatilization of the hottest part of the platinum wires).

Finally, the thermogravimetric curves that may be observed when plotted in the $\{\Delta \mathrm{m} / \mathrm{S}$ versus $\mathrm{T}\}$ scheme can be represented by one of the schematic drawings given in the Fig. (3) which also summarizes the commentaries that can be done about the different parts of the curves.

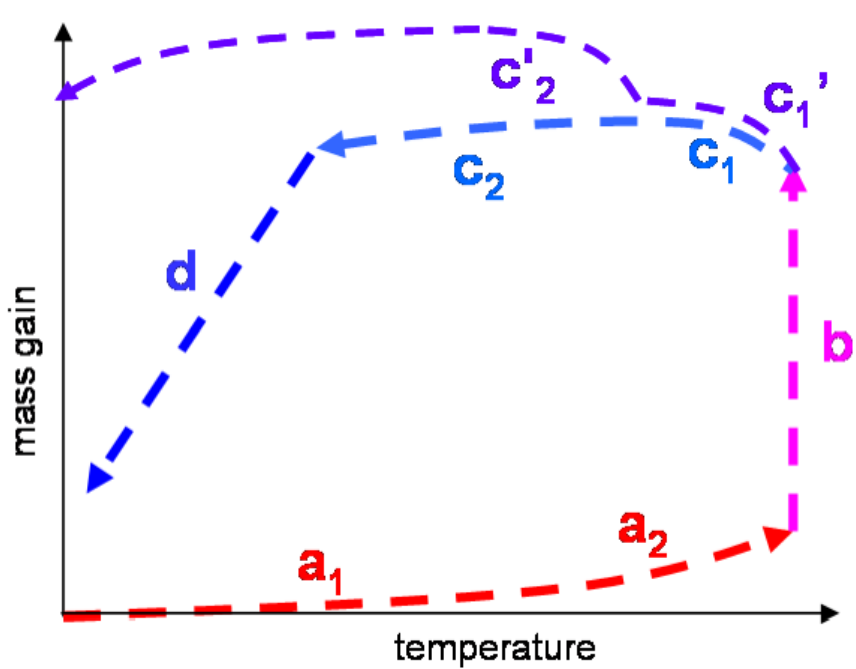

Fig. (3). Typical curves which can be encountered: ( $\left.\mathbf{a}_{\mathbf{1}}\right)$ apparent increase in mass at heating due to the decrease in Archimedes' thrust, $\left(\mathbf{a}_{2}\right)$ acceleration due to the addition of a real mass gain resulting from the starting transient oxidation, (b) isothermal mass gain essentially due to parabolic oxidation, $\left(\mathbf{c}_{\mathbf{1}}\right.$ and $\left.\mathbf{c}_{\mathbf{1}}{ }^{\prime}\right)$ mass gain due to oxidation going on at the beginning of cooling and still more important that the decrease in mass due to the increase in Archimedes' thrust, $\left(\mathbf{c}_{2}\right)$ apparent mass loss due to the increase in Archimedes' thrust and/or ( $\mathbf{c}_{2}$ ') jump due to oxide bending followed by a new rapid oxidation, (d) fast mass loss either simply caused by the acceleration of the increase in Archimedes' thrust at low temperature, or really due to spallation with a mass loss added to the first one.

\section{RESULTS}

The curves representing the variation of the mass gain per surface unit $(\Delta \mathrm{m} / \mathrm{S})$ versus temperature are given for all the tantalum-free alloys in Fig. (4) for the tests performed at a dwell temperature equal to $1000^{\circ} \mathrm{C}$, in Fig. (5) for $1100^{\circ} \mathrm{C}$ and in Fig. (6) for $1200^{\circ} \mathrm{C}$. The curves corresponding to the tantalum-containing alloys are presented in Fig. (7A) for $1000^{\circ} \mathrm{C}$, Fig. (7B) for $1100^{\circ} \mathrm{C}$ and Fig. (7C) for $1200^{\circ} \mathrm{C}$, in which the curves of the tantalum-free alloys with the same carbon contents are added again for comparison. The parameters of the curves which will be used thereafter to quantitatively characterize spallation are presented by some examples in Fig. (5A) in the case of the Co30Cr oxidized at $1100^{\circ} \mathrm{C}$

Generally, the tests started with an apparent slow increase in mass which was only due to the decrease in Archimedes' thrust because of the heating of the oxidizing gas surrounding the sample. When the temperature was high enough, oxidation started and induced an additional increase in mass. During the dwell at the temperature targeted for the test, oxidation was initially fast because of the transient linear oxidation, then the latter was rapidly replaced by parabolic oxidation, the rate of which decreased according to the Wagner's law. Oxidation (and mass gain) went on at the beginning of cooling, and after a sufficient cooling, the effect of the increasing Archimedes' thrust became more important than the mass gain due to oxidation which slowed down. Then, the measured sample mass decreased, firstly slowly then it fell more or less suddenly, with a more or less 
(A)

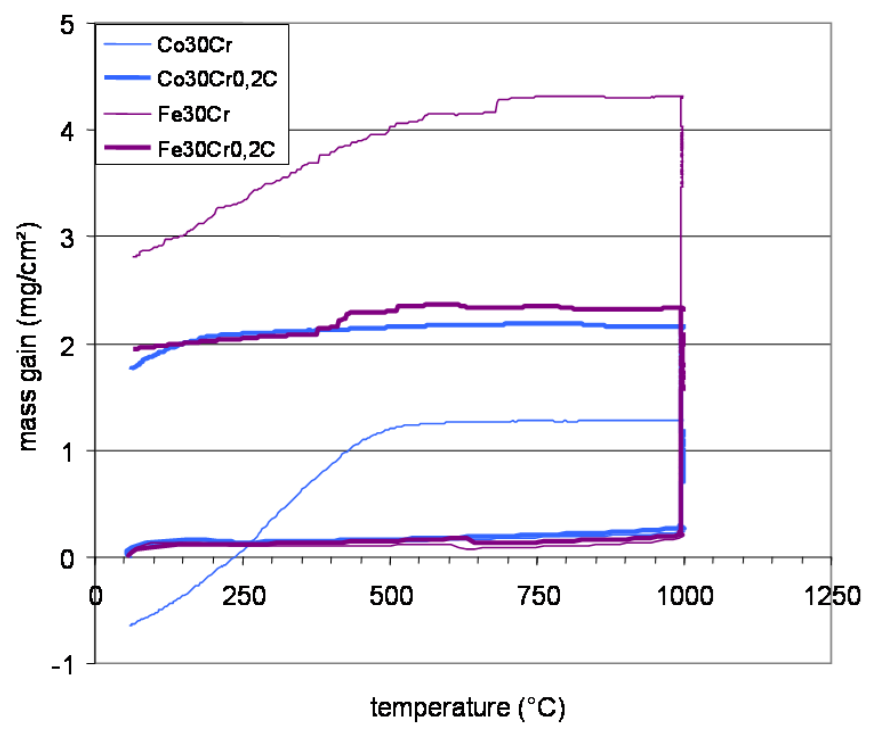

(B)

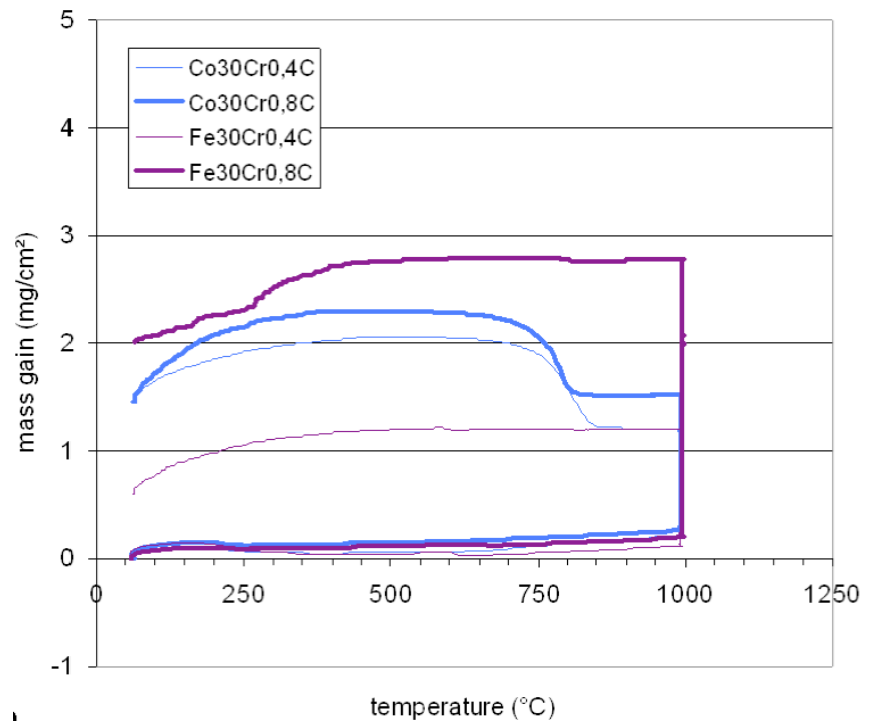

Fig. (4). $\Delta \mathrm{m} / \mathrm{S}$ plotted versus temperature, from results obtained at $1000^{\circ} \mathrm{C}$ for the low carbon $(0$ and $0.2 \mathrm{wt} . \%, \mathbf{A})$ and high carbon (0.4 and 0.8 wt. $\%$, B $)$ alloys.

high mass loss rate. In contrast, in few cases the cooling part of the curve was affected by a more or less sudden jump (increase in mass gain) induced by a more or less important detachment of the oxide scale which was responsible to a new fast oxidation of the underlying denuded alloy.

Plotting, versus the carbon content, the mass gain obtained at the end of dwell for all alloys and all dwell temperatures together, allows seeing first that the isothermal oxidation was naturally faster when the dwell temperature was higher (Fig. 8A, B). The isothermal mass gain was also higher for the Ta-free cobalt alloys than for the Ta-free iron alloys for $1200^{\circ} \mathrm{C}$ and for the $\mathrm{Co} 30 \mathrm{Cr}$ alloy than for the $\mathrm{Fe} 30 \mathrm{Cr}$ alloy at $1100^{\circ} \mathrm{C}$, while there are no significant differences in the other cases. The binary Co-based alloy obviously oxidized significantly faster than the ternary Co-based alloys at the two highest temperatures, except the alloy with
(A)

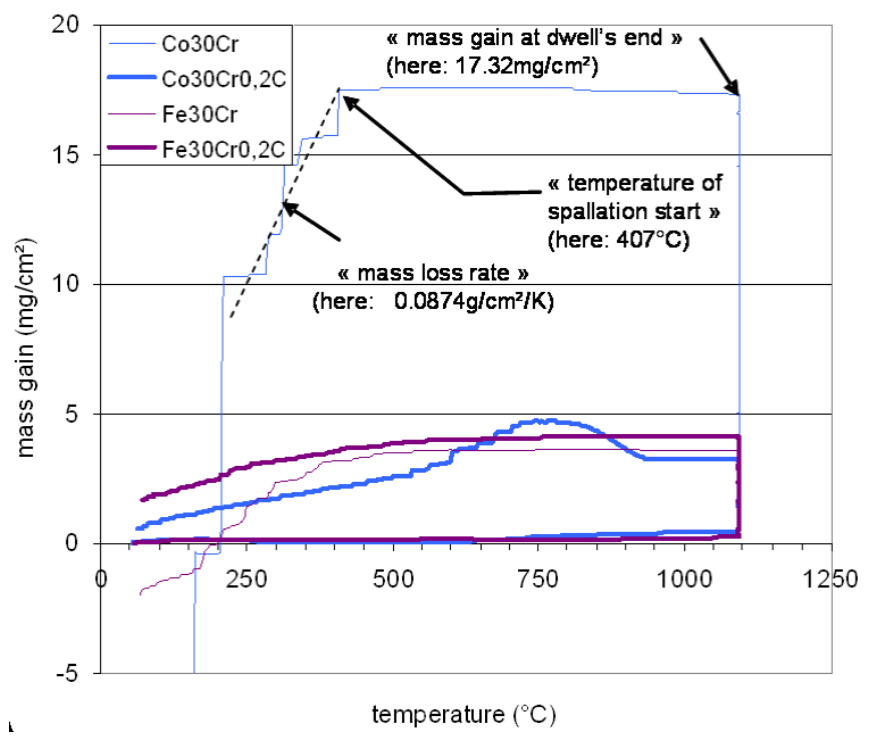

(B)

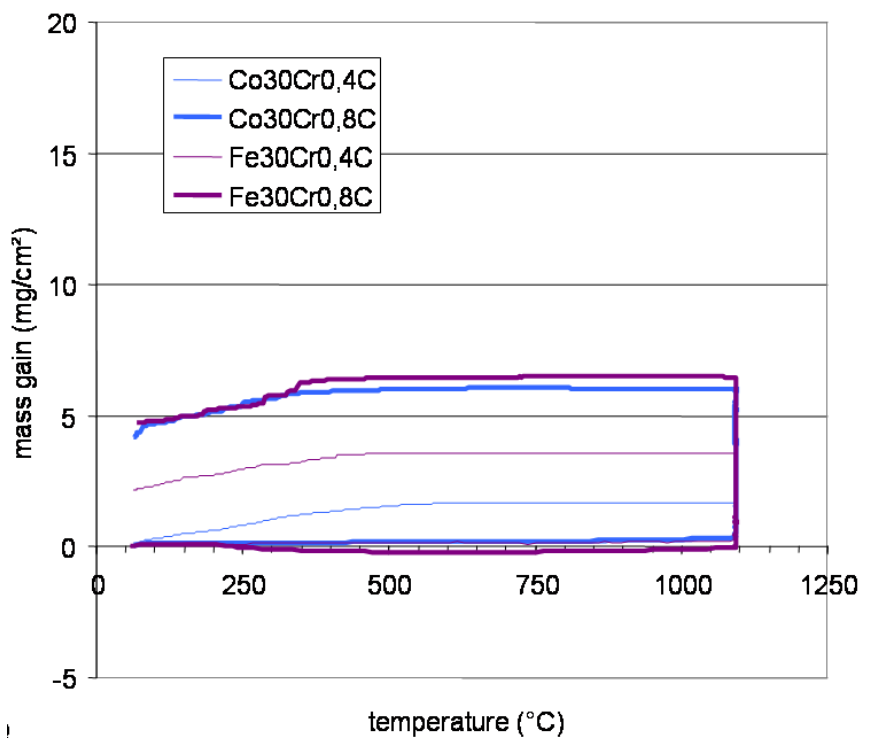

Fig. (5). $\Delta \mathrm{m} / \mathrm{S}$ plotted versus temperature, from results obtained at $1100^{\circ} \mathrm{C}$ for the low carbon $(0$ and 0.2 wt. $\%, \mathbf{A})$ and high carbon $(0.4$ and 0.8 wt.\%, B) alloys.

$0.8 \% \mathrm{C}$ which underwent at $1200^{\circ} \mathrm{C}$ a much faster oxidation. In contrast, the iron alloys did not show significant differences of behavior for the different carbon contents. Except for the cobalt alloys at $1200^{\circ} \mathrm{C}$, the Ta-containing alloys were generally oxidized slightly faster than the Ta-free alloys with the same carbon content.

Oxide spallation during the cooling, revealed in the thermogravimetric curves by a mass loss rate significantly higher than for the apparent mass loss due to the Archimedes' thrust increase (and sometimes also by an irregular cooling part of the curve), obviously occurred for the binary $\mathrm{Co} 30 \mathrm{Cr}$ and $\mathrm{Fe} 30 \mathrm{Cr}$ for all temperatures of dwell, for all alloys previously oxidized at $1200^{\circ} \mathrm{C}$ (except two of the Fe-based alloys) and for the two Ta-containing alloys after oxidation at 1100 or $1200^{\circ} \mathrm{C}$. For the cobalt alloys (Fig. 9A), there is no real or systematic relations between on the one hand the decrease in 
(A)

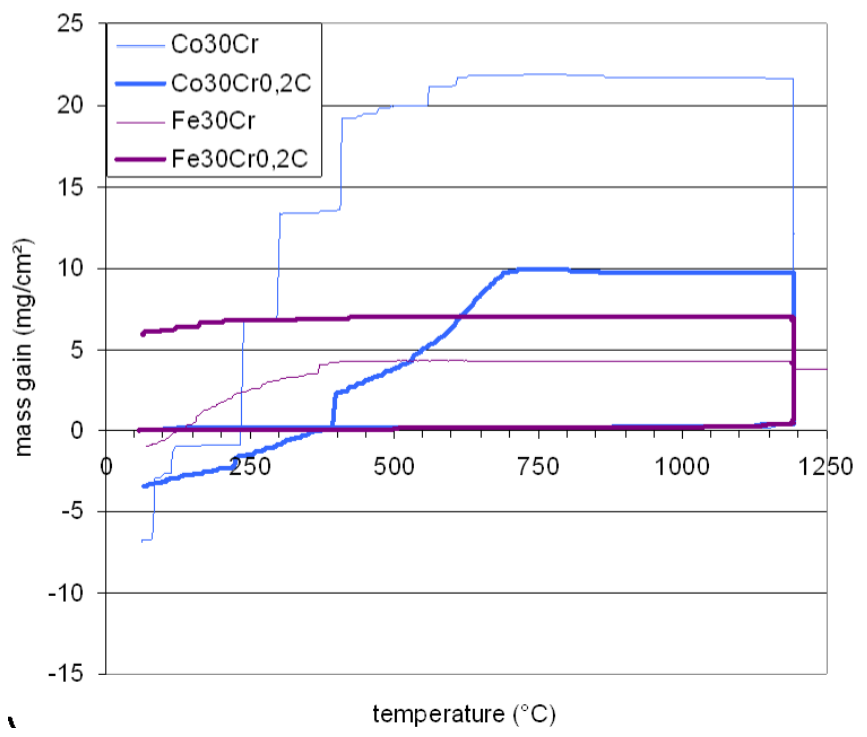

(B)

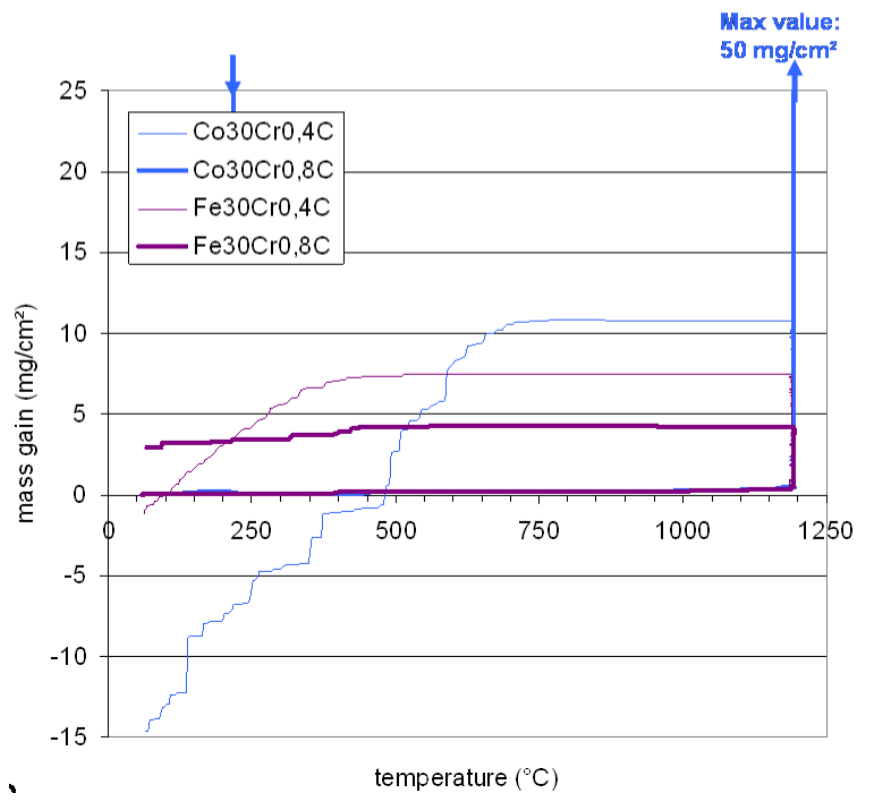

Fig. (6). $\Delta \mathrm{m} / \mathrm{S}$ plotted versus temperature, from results obtained at $1200^{\circ} \mathrm{C}$ for the low carbon $(0$ and 0.2 wt.\%, A) and high carbon $(0.4$ and $0.8 \mathrm{wt} . \%, \mathrm{~B})$ alloys.

temperature from the dwell before spallation, and on the other hand the temperature of the isothermal dwell or the carbon content of the alloy (for $1200^{\circ} \mathrm{C}$ ). For the iron-based alloys (Fig. 9B), in contrast, the decrease in temperature before spallation seems to be more important for a high temperature of isothermal dwell than for a lower temperature of dwell. In the two families of alloys, the presence of tantalum seems having a systematic effect since the decrease in temperature before spallation is generally lower for the Tacontaining alloys than for the Ta-free ones, as is to say spallation occurred earlier during cooling when Ta was present than when there was no tantalum in the alloys. Concerning the mass loss rates, they are much higher for the cobalt alloys (Fig. 10A) than for the iron alloys (Fig. 10B) while these rates seem to be lowered by the presence of tantalum.

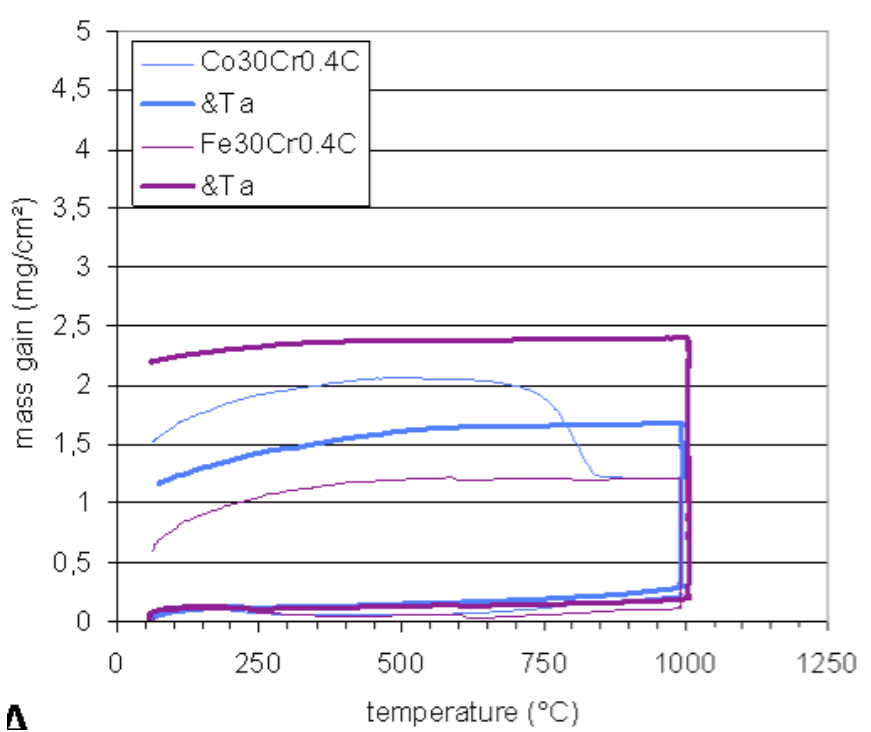

Fig. (7A). $\Delta \mathrm{m} / \mathrm{S}$ plotted versus temperature, from results obtained at $1000^{\circ} \mathrm{C}$ for the medium carbon $(0.4 \mathrm{wt} . \%)$ alloys and the tantalum-containing medium carbon alloys.

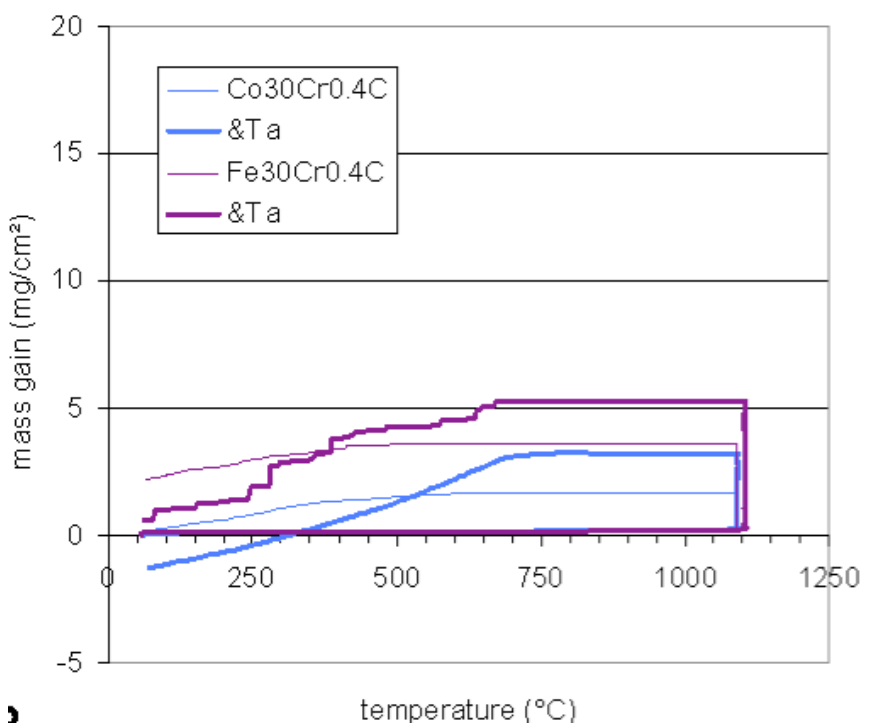

Fig. (7B). $\Delta \mathrm{m} / \mathrm{S}$ plotted versus temperature, from results obtained at $1100^{\circ} \mathrm{C}$ for the medium carbon $(0.4 \mathrm{wt} . \%)$ alloys and the tantalumcontaining medium carbon alloys.

By considering the cobalt alloys oxidized at $1200^{\circ} \mathrm{C}$ notably, it seems that the total mass gain at the end of the isothermal dwell and the two characteristics of spallation (decrease in temperature and mass loss rate) could be correlated. Thus, it is interesting to plot also the decrease in temperature before spallation and the mass loss rate, versus the total mass gain at the dwell's end, what is done respectively in Fig. (11A, B) (of course only for the alloys affected by spallation). For the cobalt alloys the decrease in temperature before spallation increases with the mass gain (about $10^{\circ} \mathrm{C}$ per $\mathrm{mg} / \mathrm{cm}^{2}$ for the tantalum-free cobalt alloys). In contrast, there is no obvious dependence for the iron alloys. However, in the two cases, the decrease in temperature before spallation seems to be significantly decreased by the presence of tantalum in the iron alloys while there is no obvious effect in the case of the cobalt alloys. When the mass loss rates are 


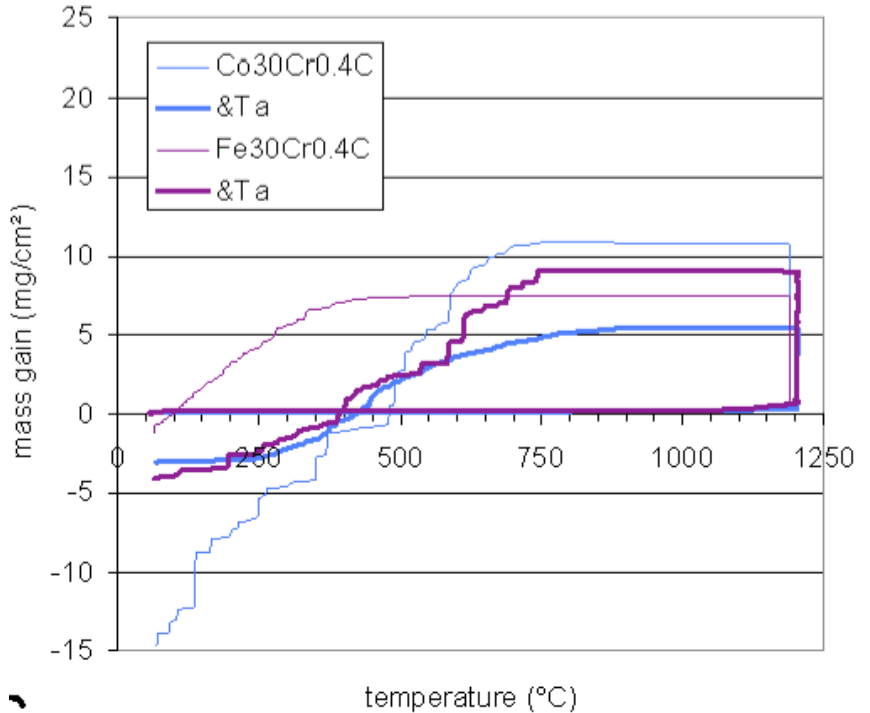

Fig. (7C). $\Delta \mathrm{m} / \mathrm{S}$ plotted versus temperature, from results obtained at $1200^{\circ} \mathrm{C}$ for the medium carbon $(0.4$ wt.\%) alloys and the tantalum-containing medium carbon alloys.

(A)
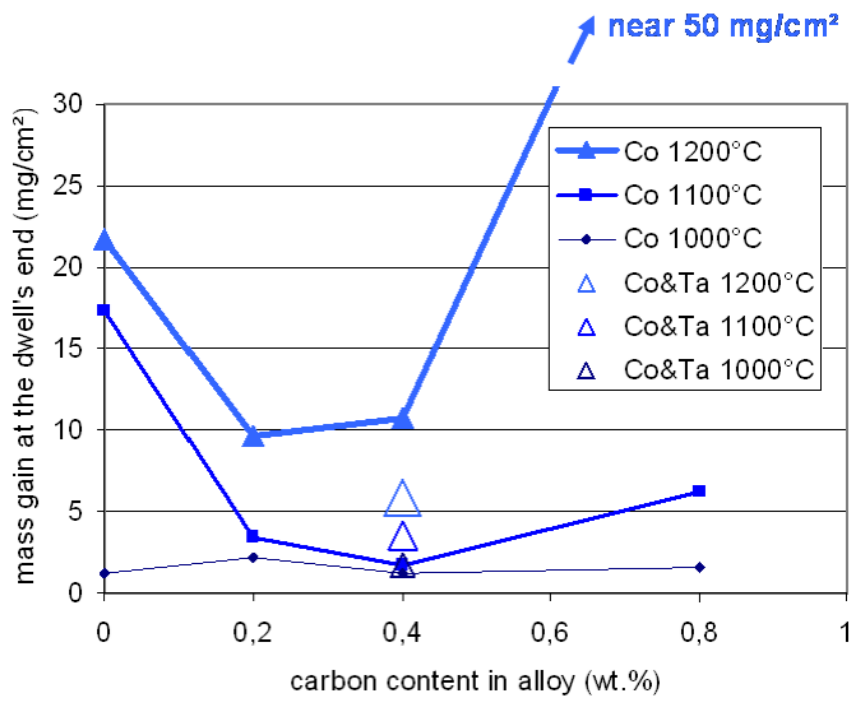

(B)

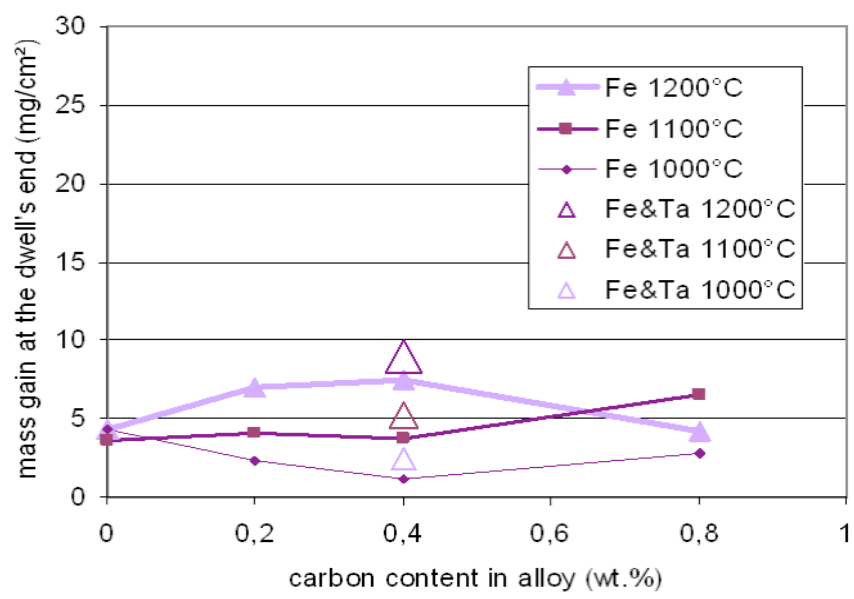

Fig. (8). Mass gain at the end of dwell for the cobalt alloys (A) and the iron alloys (B) plotted versus the carbon weight content of the alloys.
(A)

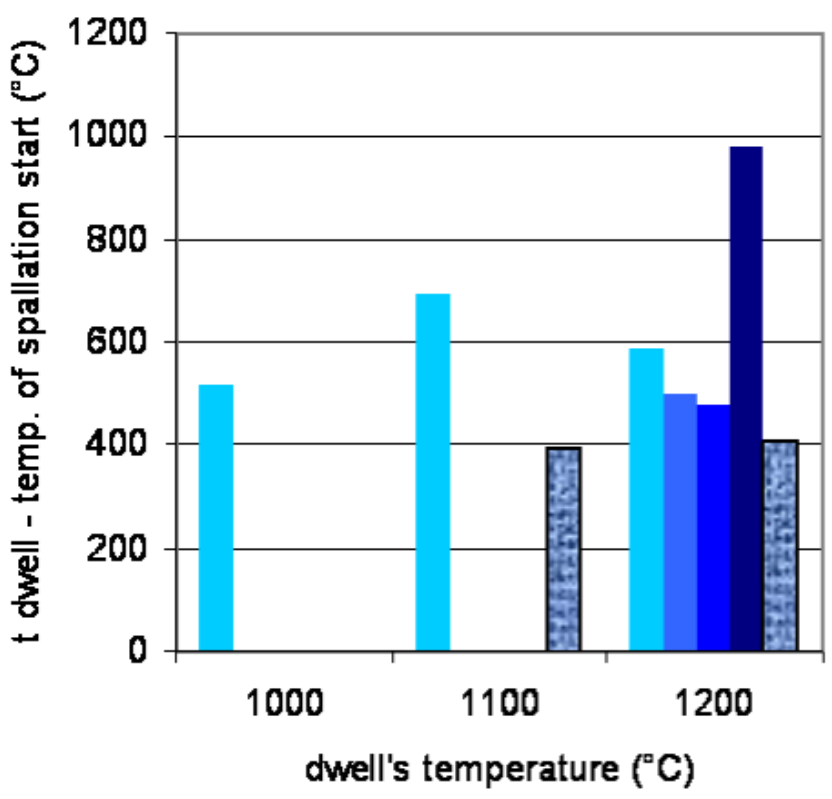

$\mathrm{C} 030 \mathrm{Cr} \square \& 0.2 \mathrm{C} \square \& 0.4 \mathrm{C} \square \& 0.8 \mathrm{C} \square 0.4 \mathrm{C} \& \mathrm{Ta}$

(B)

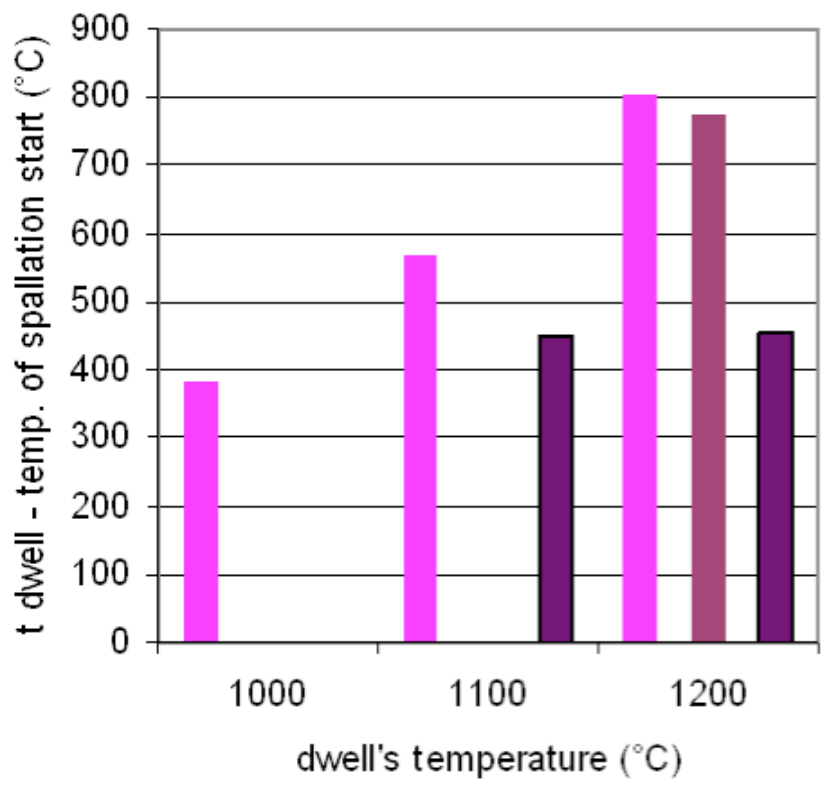

$\mathrm{Fe} 30 \mathrm{Cr} \square \& 0.2 \mathrm{C} \square \& 0.4 \mathrm{C} \square \& 0.8 \mathrm{C} \square 0.4 \mathrm{C} \& \mathrm{Ta}$

Fig. (9). Decrease in temperature from the dwell temperature before the beginning of spallation, for the cobalt-alloys (A) and the ironbased alloys (B).

considered one can see a more evident dependence on the mass gain at the end of the dwell: indeed, for all alloys taken together, the mass loss rate increases when the mass gain at dwell's end, with a slope of about $3 \times 10^{-3} \mathrm{mg} / \mathrm{cm}^{2} /{ }^{\circ} \mathrm{C}$ by $\mathrm{mg} / \mathrm{cm}^{2}$. Similarly to the decrease in temperature before spallation, tantalum seems lowering the mass loss rates of the iron alloys while it does not induce any effect for the cobalt alloys. 
(A)

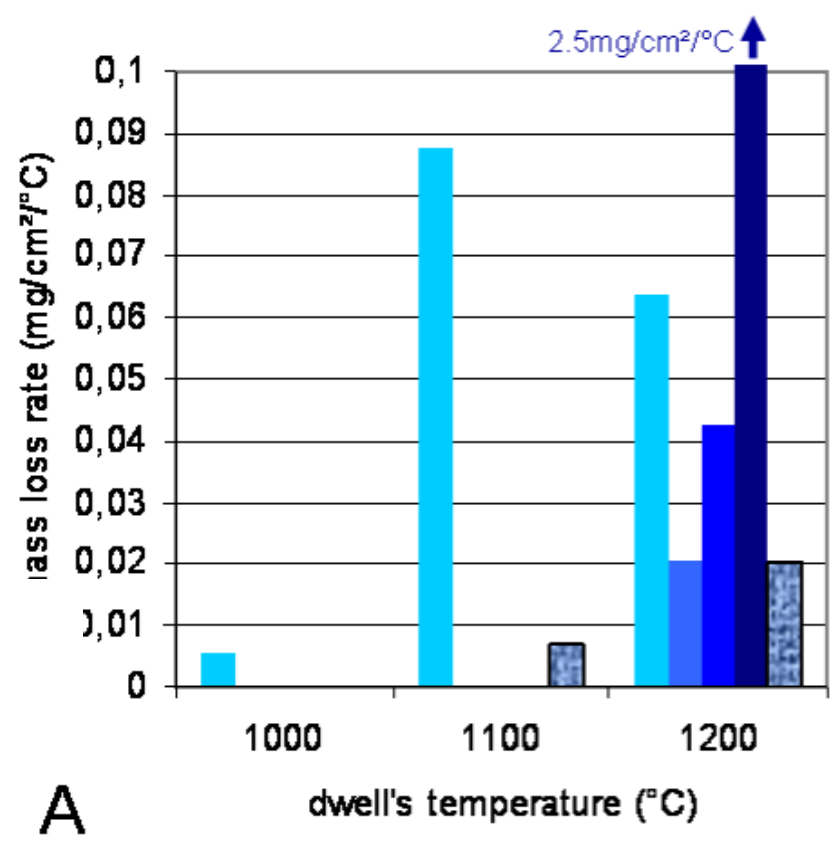

$\mathrm{C} 03 . \mathrm{Cr} \square \& 0.2 \mathrm{C} \square \& 0.4 \mathrm{C} \square \& 0.8 \mathrm{C} \square 0.4 \mathrm{C} \& \mathrm{Ta}$

(B)

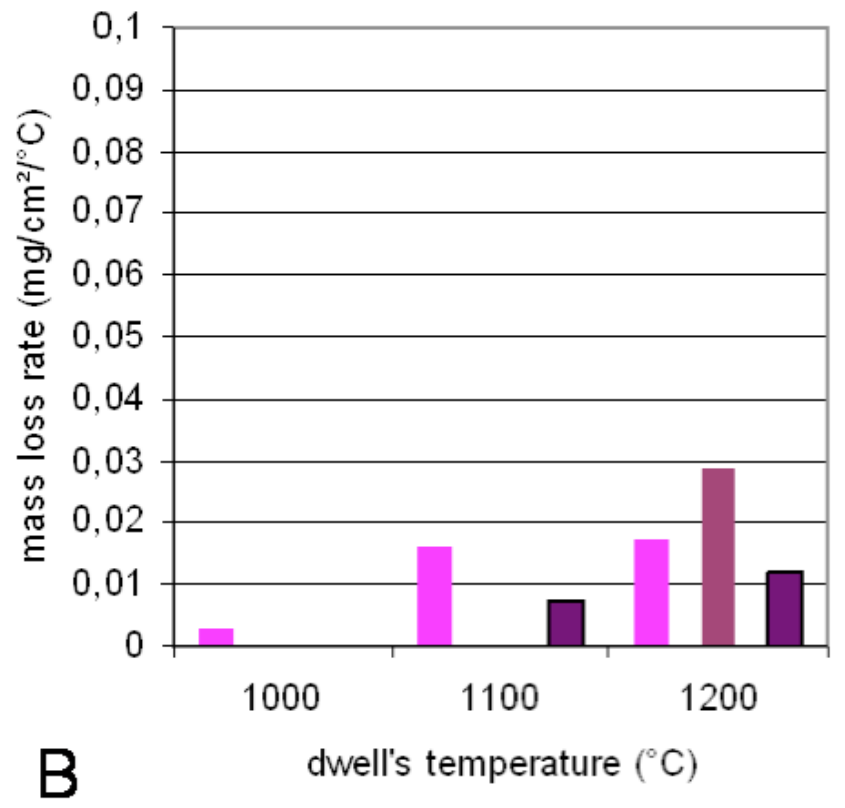

$\mathrm{Fe} 30 \mathrm{Cr} \backsim \& 0.2 \mathrm{C} \square \& 0.4 \mathrm{C} \square \& 0.8 \mathrm{C} \square 0.4 \mathrm{C} \& \mathrm{Ta}$

Fig. (10). Mass loss rate due to oxide spallation, for the cobaltalloys (A) and the iron-based alloys (B).

The selected BSE micrographs displayed in Fig. (12) for the cobalt alloys, and in Fig. (13) for the iron alloys, result from SEM examinations of the oxidized surfaces, while the natures of the different oxides were controlled by WDS measurements of their chemical compositions. Concerning the cobalt-based alloys, several surfaces states were noticed. Few external oxides still exist over the Co-30Cr sample and
(A)

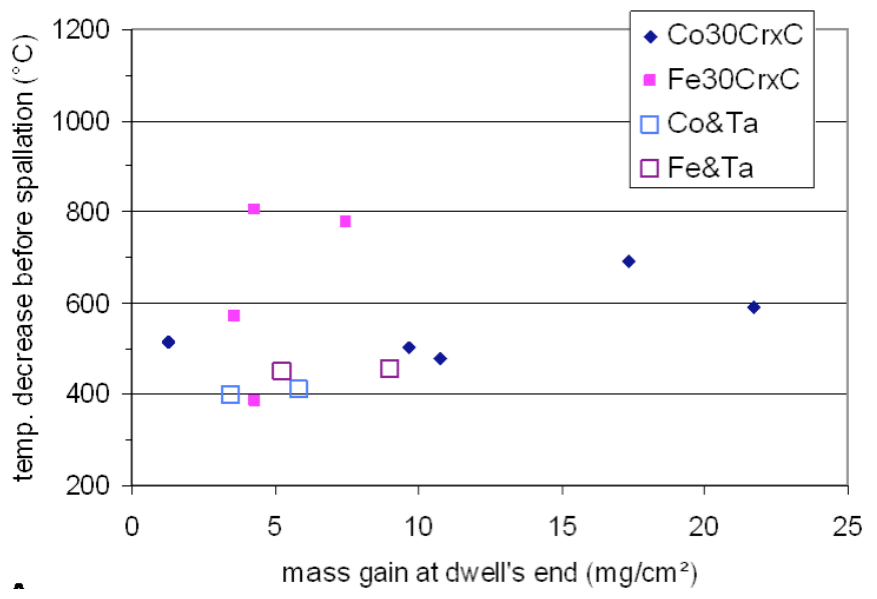

(B)

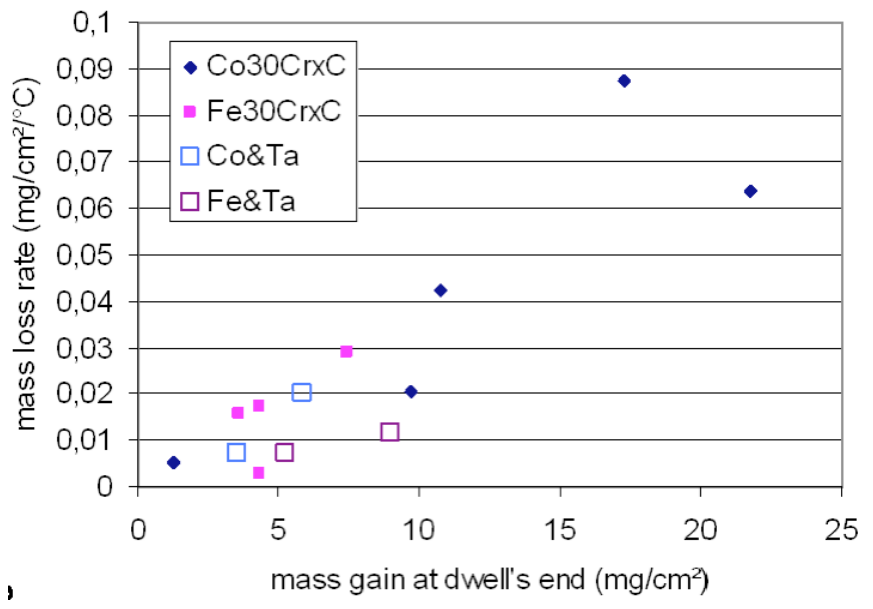

Fig. (11). Difference between the temperature at which spallation begins during cooling and the dwell temperature (A) and rate of mass loss during cooling (B), plotted versus the mass gain isothermally achieved.

they are rather $\mathrm{Cr}_{2} \mathrm{O}_{3}$. They are more numerous over the Co$30 \mathrm{Cr}-0.2 \mathrm{C}$ sample $\left(\mathrm{Cr}_{2} \mathrm{O}_{3}+\mathrm{CoO}\right)$, while many oxides exists over the $\mathrm{Co}-30 \mathrm{Cr}-0.4 \mathrm{C}$ and $\mathrm{Co}-30 \mathrm{Cr}-0.8 \mathrm{C}$ samples for which an outer waved $\mathrm{Cr}_{2} \mathrm{O}_{3}$ layer remains more or less attached to an inner adherent $\mathrm{CoO}$ scale. At $1100^{\circ} \mathrm{C}$, the $\mathrm{Co}-30 \mathrm{Cr}$ alloy obviously underwent a catastrophic oxidation into porous spinel oxides which can be still noticed in several locations on the metallographic sample. For the Co-30Cr- $0.2 \mathrm{C}$ some detached $\mathrm{Cr}_{2} \mathrm{O}_{3}$ outer oxides were present over adherent $\mathrm{CoO}$ oxides in other locations. For the two C-richest alloys, the external oxide scale is almost present and adherent everywhere, but it is composed of different types of oxides $(\mathrm{CoO}$, $\mathrm{Cr}_{2} \mathrm{O}_{3}$ and sometimes small parts of spinel). The samples oxidized at $1200^{\circ} \mathrm{C}$ all present thick spinel oxides, more or less lost during cooling. The case of the tantalum-containing alloy is different since the external oxide is $\mathrm{Cr}_{2} \mathrm{O}_{3}$, with presence of films of another oxide containing tantalum $\left(\mathrm{CrTaO}_{4}\right)$, while other $\mathrm{CrTaO}_{4}$ oxides are also present in the sub-surface (with a more compact shape).

Concerning the iron-based alloys, there are much less differences between the alloys and between the test temperatures. Indeed, a $(\mathrm{Fe}, \mathrm{Cr})_{2} \mathrm{O}_{3}$ external oxide can be seen all 


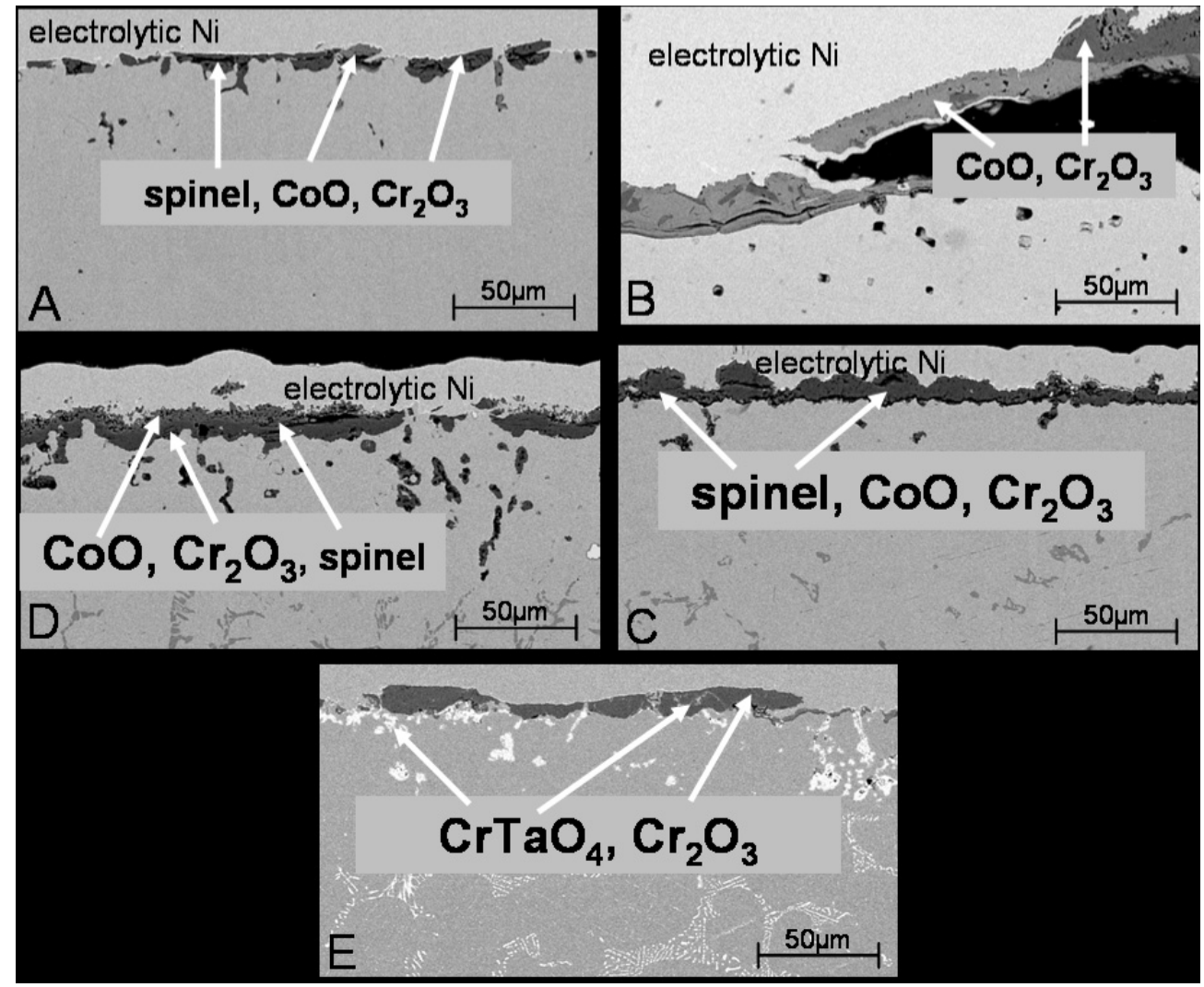

Fig. (12). Some SEM/BSE micrographs illustrating the surface states of the Co-based alloys after oxidation at $1100^{\circ} \mathrm{C}$ during 50 hours and cooling at $-5^{\circ} \mathrm{C} \mathrm{min}^{-1}$ down to room temperature $(\mathbf{A}$ : $\mathrm{Co} 30 \mathrm{Cr}, \mathbf{B}$ : $\mathrm{Co} 30 \mathrm{Cr} 0.2 \mathrm{C}, \mathbf{C}$ : Co30Cr0.4C, D: Co30Cr0.8C, E: Co30Cr0.4C+Ta).

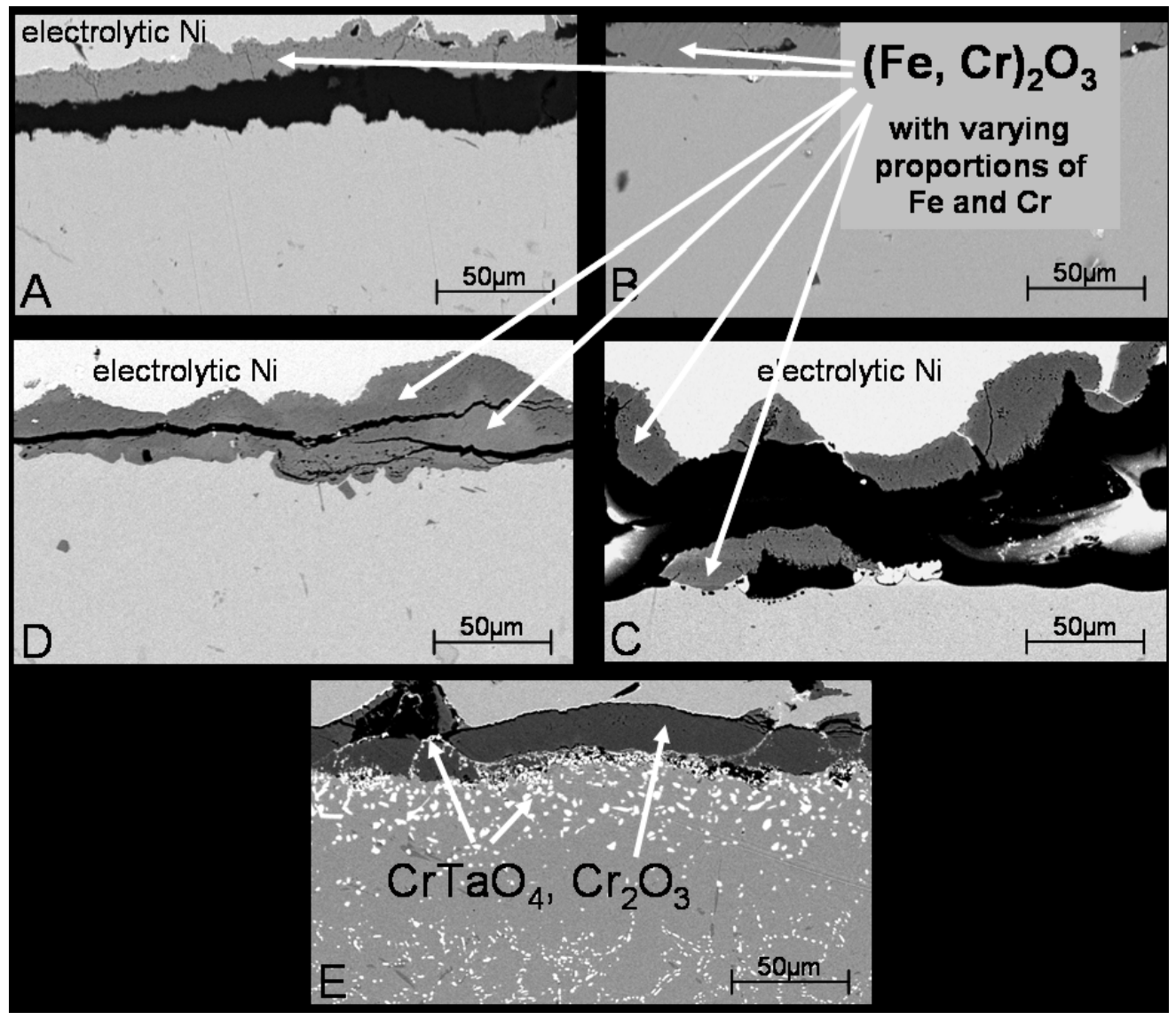

Fig. (13). Some SEM/BSE micrographs illustrating the surface states of the Fe-based alloys after oxidation at $1100^{\circ} \mathrm{C}$ during 50 hours and cooling at $-5^{\circ} \mathrm{C} \min ^{-1}$ down to room temperature (A: Fe30Cr, B: Fe30Cr0.2C, C: Fe30Cr0.4C, D: Fe30Cr0.8C, E: Fe30Cr0.4C+Ta). 
around all samples, more or less thick, rich in $\mathrm{Cr}$ (or in $\mathrm{Fe}$ ) or detached from the substrate. The Fe content and $\mathrm{Cr}$ content both vary in the external $\mathrm{M}_{2} \mathrm{O}_{3}$ scale along the surface of a same alloy. As for the cobalt alloy, the presence of tantalum also led to an external chromia scale mixed with films of $\mathrm{CrTaO}_{4}$ oxides and to other $\mathrm{CrTaO}_{4}$ oxides in the subsurface.

\section{DISCUSSION}

During the cooling, it is well known that an alloy undergoes a thermal contraction, inverse to the thermal expansion which occurred during the heating before the isothermal dwell. In the heating part of the experiment, this had not real importance for the external oxide since only few dispersed oxides existed on the surface (when the temperature was high enough). In contrast, during the cooling a more or less thick continuous external oxide scale exists and is subjected to increasing mechanical stresses (biaxial compression in the oxide thickness and shear at the oxide-alloy interface) since the thermal expansion coefficients of oxides are usually significantly lower than the alloy's ones $[8,9]$. This may lead to breakdowns and losses of the external oxide [1] as illustrated in Fig. (1, left) or to its local folding (Fig. 1, right) or generalized detachment from the substrate. Such phenomena were clearly seen on the cooling part of the thermogravimetric curves for the alloys of this study. Indeed, folding of the external scale occurred for example in the case of the two ternary cobalt alloys with 0.4 and $0.8 \mathrm{wt} . \% \mathrm{C}$ at $1000^{\circ} \mathrm{C}$ (jumps of mass gain, Fig. 4B) while more or less continuous spallation of the oxide scale, revealed by mass losses beginning at high temperature or by especially fast mass loss rates (too fast to be due to the increase in Archimedes' thrust) at lower temperatures. Nevertheless some parts of oxides remained on the surfaces of the oxidized samples and they allowed characterizing their natures.

By their natures as well as by their features, these oxidation products well correspond to classical cases as well as to previous observations done for other alloys belonging to the same families, even if a great part of the scale was lost by spallation and then only its inner parts are still on surface. Indeed, $\mathrm{Cr}_{2} \mathrm{O}_{3}$ and $\mathrm{CoO}$ separately appeared during transient oxidation may have not totally reacted together (e.g. $\mathrm{Cr}_{2} \mathrm{O}_{3}+\mathrm{CoO}->$ spinel $\mathrm{CoCr}_{2} \mathrm{O}_{4}$ ) because of too low test temperatures and duration $[1,10]$. External continuous $\mathrm{Cr}_{2} \mathrm{O}_{3}$ and internal $\mathrm{CrTaO}_{4}$ were already met in chromia-forming TaC-containing cobalt-based and iron based alloys (e.g. [11, $12]$ ), and external $(\mathrm{Fe}, \mathrm{Cr})_{2} \mathrm{O}_{3}$ scales with varying contents in $\mathrm{Fe}$ and $\mathrm{Cr}$ were also encountered for chromium-containing iron-based alloys $[10,13]$.

Fast oxidation with spinel $\mathrm{CoCrO}_{4}$ formation, with consequently especially high mass gains at the end of isothermal dwell occurred at the two highest temperatures for the tantalum-free cobalt alloys with the two extreme contents in carbon. The binary Co30Cr was obviously victim of the difficulty of chromium diffusion which is less easy in volume for a cobalt matrix than for example for a nickel matrix, and which was not helped by the grain boundaries diffusion because of the absence of intergranular chromium carbides. This chromium diffusion along grain boundaries was seemingly easier for the medium-carbon alloys, while, for the carbon-richest alloy the precipitation at solidification of a too high fraction of chromium carbides had seemingly too decreased the chromium concentration in the matrix, with consequently the loss of its chromia-forming behavior. The presence of tantalum, in contrast, allowed keeping all chromium in the matrix since the single type of carbides was $\mathrm{TaC}$, the presence of which in grain boundaries nevertheless helped diffusion. However, it is true that internal oxidation of tantalum was in addition responsible of slightly increased mass gains. Tantalum similarly acted in the case of the Febased alloys, which were less threatened by fast oxidation anyway, thanks to the $(\mathrm{Cr}, \mathrm{Fe})_{2} \mathrm{O}_{3}$ external oxide.

About the parameters influencing the spallation phenomenon for the studied alloys, it appears that they are multiple: (1) the base element, (2) the presence or not of carbides, (3) the presence or not of another very oxidable element, (4) the temperature at which the isothermal oxidation was realized and (5) the quantity of oxide formed prior to cooling.

1. It was effectively seen first that, when spallation begins the mass loss rate was higher for the cobalt alloys than for the iron alloys. This can be related to differences of thermal expansion (or contraction) coefficient $(\alpha)$ between the two families [14]: the thermal contraction of Fe-based alloys ( $\alpha$ of about $15 \mathrm{x}$ $10^{-6} \mathrm{~K}^{-1}$ ) is significantly slower than for the similar Co-based alloys (about $20 \times 10^{-6} \mathrm{~K}^{-1}$ ). The behaviors of $\mathrm{Fe}-30 \mathrm{Cr}-\mathrm{xC}$ alloys in thermal expansion, and in thermal contraction, are then closer to the oxides' ones (about $10 \times 10^{-6} \mathrm{~K}^{-1}$ ), with therefore less compression stress induced in the external oxide scale. But this had here no real consequences for the decrease in temperature before spallation.

2. The carbide-free binary alloys were subjected to spallation in all cases, contrarily to the carbidescontaining alloys which encountered spallation only at the highest or at the two highest temperatures. There are two possible reasons for that: a thermal contraction slightly lower when carbides are present, or a better adherence of the oxide on surface due to a higher tendency for a more internal oxidation in the grain boundaries emerging in surface.

3. The effect of spallation of such elements more easily oxidable than chromium was already studied in previous studies notably concerning iron alloys [15]. Here it was seen that selective oxidation of tantalum led to the presence of another type of oxide in the outer part of the Ta-containing alloys, $\mathrm{CrTaO}_{4}$, which separated the external oxide from the alloys, with seemingly a worse adherence of the oxide scale responsible to both an earlier spallation's beginning at cooling and a higher mass loss rate. Obviously, for a same initial mass of oxide on the sample surface, tantalum influenced more the iron alloys than the cobalt alloys.

4. and (5): a high temperature of isothermal oxidation and a bad behavior in oxidation both led to thicker oxide scales before cooling, which are logically more threatened by spallation thereafter: this can result in an earlier spallation (lower decrease in temperature before start of spallation) and in a faster mass loss. 


\section{CONCLUSION}

Spallation of external oxide scales at ppost - high temperature oxidation \} cooling is a serious problem for high temperature alloys. This phenomenon is often characterized using specific experiments (cyclic oxidation). However, if thermogravimetry results of isothermal oxidation kinetic are available, the cooling parts of such curves can give preliminary useful quantitative indications (temperature of spallation start, mass loss rate, ...) concerning the sequences of spallation which led to the absence, or to the pleating and local detachments, of the external oxide scales as it can be seen around the samples before or after metallographic preparation. By this mean some interesting comparisons were here possible to do between ternary cobalt-based alloys and analogous alloys based on iron, with or without addition of tantalum.

\section{ACKNOWLEDGEMENTS}

The author gratefully thanks Lionel Aranda who performed the thermogravimetry runs, as well as the Common Service of Microscopy and Microanalyses of the Faculty of Science and Techniques of the University Henri Poincaré Nancy 1.

\section{REFERENCES}

[1] Kofstad P. High Temperature Corrosion. Elsevier applied science; London 1988.

[2] Wagner C. The theory of the warm-up process. Z Phys Chem 1933; 21(1/2): 25-41.

[3] Wasielewski GE, Rapp RA. High-temperature oxidation. In: Sims CT, Hagel WC, Eds. The Superalloys. John Wiley \& Sons: New York 1972; pp. 287-316.
[4] Bradley EF, Ed. Superalloys: a technical guide. ASM International; Metals Park 1988.

[5] Baleix S, Bernhart G, Lours P. Investigation of the spallation of oxides grown on thermally cycled heat resistant cast steels. Mater Sci Forum 2001; 369-72(1): 539-46.

[6] Pettersson RFA, Enecker J, Liu L. Role of nickel in the oxidation of $\mathrm{Fe}-\mathrm{Cr}-\mathrm{Ni}$ alloys in air-water vapour atmospheres. Mater High Temp 2005; 22(3-4): 269-81.

[7] Kartono R, Monceau D, Young DJ. Continuous thermogravimetric analysis during the cyclic oxidation of Ni-22Al-15Pt $+1 \mathrm{wt} . \% \mathrm{Hf}$ at $1200^{\circ} \mathrm{C}$. Scr Mater 2007; 57: 647-50.

[8] Shaffer P. Plenum Press Handbooks of High-Temperature Materials: $\mathrm{N}^{\circ} 1$ materials index. Plenum Press: New York 1964.

[9] Samsonov GC. Plenum Press Handbooks of High-Temperature Materials: N’2 properties index. Plenum Press: New York 1964.

[10] Berthod P. Influence de l'élément de base et de la densité des carbures sur l'oxydation à haute temperature d'alliages M-30Cr-xC $(\mathrm{M}=\mathrm{Co}, \mathrm{Ni}, \mathrm{Fe})$. Partie II : Caractérisation de la microstructure subcorticale. Ann Chim Sci Mat 2008; 33(3): 247-65.

[11] Berthod P, Raude S, Renck AS, Rapin C, Podor R, Steinmetz P. Influence of the microstructural texture of cast superalloys on their high-temperature oxidation behaviour. Mater Sci Forum 2004; 461464: 1173-80.

[12] Berthod P, Hamini Y, Aranda L. Influence of tantalum on the rates of high temperature oxidation and chromia volaitilization for cast (Fe and/or Ni)-30Cr-0.4C alloys. Mater Sci Forum 2008; 595-598: 861-70.

[13] Rajendran Pillai S, Dayal RK. Cyclic oxidation of P91 by thermogravimetry and investigation of integrity of a scale by transientmass-gain method. Oxid Met 2008; 69: 131-42.

[14] Berthod P. Influence of carbides and of the dendritic orientation on the thermal expansion of Ni-base, Co-base and Fe-base simple cast alloys. Int J Mater Res 2008; 99: 265-72.

[15] Kochubey V, Al-Badairy H, Tatlock G, Le-Coze J, Naumenko D, Quadakkers WJ. Effect of minor additions and impurities on oxidation behaviour of FeCrAl alloys. Development of novel surface coatings compositions. Mater Corros 2005; 56(12): 848-53. 